\title{
INNOVATION AND IMITATION IN AN INFORMATION AGE
}

Thomas F. Cooley

New York University

\author{
Mehmet Yorukoglu \\ University of Chicago
}

\begin{abstract}
We study the behavior of imitation and innovation in a dynamic general equilibrium model that captures the salient features of an information age. We study a world where innovations can be made but at a cost that reflects the type of goods. After innovation takes place, imitation is possible but again at some cost which reflects the nature of the good. We show that the behavior of innovation and imitation are very different for high information content goods and low information content goods and this has important implications for the structure and evolution of industry. (JEL: O31, L16)
\end{abstract}

\section{Introduction}

The traditional view of the problem of intellectual property protection is that a welfare maximizing government faces a well understood trade-off. Strengthening the protection of intellectual property provides incentives for innovation and the benefits that flow from having more and better products. The downside is that protection limits imitation and competition and thus limits the benefits that households can realize from existing products. Imitation, even the threat of imitation, can be socially beneficial because it facilitates the diffusion of new products. There is a substantial literature that has analyzed optimal policies for protecting intellectual property. In addition there has been a substantial public policy debate about the wisdom of protecting certain kinds of intellectual property and about how heavily protection should be monitored. An important part of this recent debate has centered on the issue of whether certain types of goods, those with high information content, should be protected at all. In this paper we address this issue but with a much narrower question in mind. As a prelude to thinking about what protection should be, we examine how the process of innovation and imitation differ for high information content goods versus low information content goods.

In Cooley and Yorukoglu (2002) we studied the consequences of an information revolution in a world where information is a central attribute of

Acknowledgments: We thank the National Science Foundation for support through Grant SES0111518.

E-mail addresses: Cooley: tcooley@stern.nyu.edu; Yorukoglu: m_yorukoglu@chicago.edu 
goods. The key feature of information is that, once it is produced, it can be used repeatedly without much additional cost - the marginal cost of using information after it is produced is almost zero. The fact that information becomes a more important attribute of goods in an information age has important implications for innovation and for welfare. In this paper we study the behavior of imitation and innovation in a dynamic general equilibrium model that captures the salient features of an information age. We study a world where innovations can be made but at a cost that reflects the type of goods. After innovation takes place, imitation is possible but again at some cost which reflects the nature of the good. The key idea here is that, for high information content goods a larger fraction of the innovation costs will be pure R\&D costs. Goods with a higher portion of R\&D costs will be less costly to imitate. We show that the behavior of innovation and imitation are very different for high information content goods and low information content goods and this has important implications for the evolution of industry.

In a series of important papers Edwin Mansfield studied the nature of innovation and imitation in several industries. What he found was that, even with patent protection, imitation occurs quite frequently and relatively quickly after innovation. Mansfield et al. (1981) studied forty-eight important innovations in four sectors. He found that 70 percent of innovations were patented and 71 percent were imitated. He also found that imitation is faster and less costly than innovation and that the R\&D intensive goods were less costly to imitate. These findings inform the structure of our model.

In the next section we describe the structure of the model economy and the nature of innovation and imitation. We then describe the problems of an innovator and potential imitators. The following section describes the equilibrium in a world without patent protection. We use a simple parametric example to illustrate how the differences in innovation and imitation for high information goods influence industry structure and evolution.

\section{The Model}

Consider an infinite-horizon continuous time economy. The economy consists of identical households. A household's contemporaneous utility is

$$
u(\mathbf{c}, l)=\phi \log \mathbf{c}+(1-\phi) \log l, \quad 0<\phi<1,
$$

with $\mathbf{c}=\left[\int_{0}^{N} c_{i}^{\theta} d i\right]^{1 / \theta}, 0<\theta<1$, where $c_{i}$ denotes the household's consumption of good $i, N$ is the number of goods that the household consumes, and $l$ is leisure time. Households seek to maximize lifetime utility by picking consumption and leisure, i.e., at time zero their problem is

$$
\max _{\left\{\mathbf{c}_{t}, l_{t_{0}}^{\infty}\right.} \int_{0}^{\infty} u\left(\mathbf{c}_{t}, l_{t}\right) e^{-\delta t} d t, \quad \delta>0 .
$$


s.t.

$$
\int_{0}^{N_{t}} p_{i t} c_{i t} d i+\frac{d a_{t}}{d t}=w_{t}\left(1-l_{t}\right) .
$$

New goods can be innovated by incurring a one time fixed cost, $\kappa>0$. This fixed cost includes cost of product specification, pilot plant and prototype, plant and equipment, and manufacturing and marketing start-up as well as the innovation cost that goes for direct research and development. Imitating an existing product is also possible, but only if a fixed cost is paid. The fixed cost of imitating a product at age $s$ is

$$
C(s)=\lambda \kappa e^{-\rho s}+(1-\lambda) \kappa, \quad s \geq 0, \quad \rho>0,
$$

where $s$ is the time after innovation of the product. The imitation cost has two components. An imitator usually spends much less time and money on research than the innovator because the product's existence and characteristics provide a great deal of information that the innovator had to obtain through his own costly research. Let's assume that $\lambda$ is the fraction of the innovation cost that goes to research that the imitator can benefit from. The time it takes to imitate a new product can generally be reduced by spending more money. Each product's imitator is confronted by a time-cost trade-off function, which is the relationship between the amount spent by the imitator and the length of time it would take to imitate this new product. Therefore, the cost of imitation decays exponentially at rate $\rho$ after innovation, i.e., imitating a product becomes easier as the product gets older. On the other hand, an imitator often has to go through the same steps as the innovator with respect to pilot plant or prototype construction, investment in plant and equipment, training the employees, and manufacturing and marketing start-up. A $(1-\lambda)$ fraction of innovation cost represents those kind of costs which do not decay with time. In our taxonomy, high $\lambda$ goods are high information content goods.

The production technology exhibits decreasing returns to scale,

$$
f_{t}(n)=A n^{\alpha} e^{\gamma t}, \quad A>0, \quad 0<\alpha<1, \quad \gamma>1,
$$

where $n$ is the amount of labor used. This production technology is common to both the innovators and the imitators. Productivity increases exogenously at rate $\gamma$.

Households receive income from labor and from their ownership of the firms. All firms and assets are owned by households and profits generated by innovators and imitators go to them. All agents have access to a credit market where they can borrow and lend at a rate $r$.

After paying the fixed innovation cost $\kappa$, at each point in time innovating firm picks optimal price and quantity of production for its product. Let $m_{t, s}=$ $m(t, s)$ be the number of producers of the innovators's product at time $t$ including 
the innovator himself (number of imitators plus one). Then the problem of an innovating firm with a product at age $s$ will read

$$
\begin{aligned}
V_{t}^{o}(s)=\max _{p_{t, s}^{o}} \int_{0}^{\infty}\left(p_{t, s}^{o} D\left(p_{t, s}^{o} ;\left[p_{t, s}^{1}, p_{t, s}^{2}, \ldots, p_{t, s}^{m_{t, s}}\right]\right)\right. \\
\left.-w_{t}\left[\frac{D\left(p_{t, s}^{o} ;\left[p_{t, s}^{1}, p_{t, s}^{2}, \ldots, p_{t, s}^{m_{t, s}}\right]\right)}{A e^{\gamma t}}\right]^{1 / \alpha}\right) e^{-\delta t} d t .
\end{aligned}
$$

where $D\left(p_{t, s}^{o} ;\left[p_{t, s}^{1}, p_{t, s}^{2}, \ldots, p_{t, s}^{m_{t, s}}\right]\right)$ is the demand for the product of the firm given the prices charged; $p_{t, s}^{o}$ is the price that the innovator charges, and $p_{t, s}^{i}$ is the price that the $i$ th imitator charges. Here the amount of labor used by the innovating firm is $n_{t, s}=\left[D\left(p_{t, s}^{o} ;\left[p_{t, s}^{1}, p_{t, s}^{2}, \ldots, p_{t, s}^{m_{t, s}}\right) / A e^{\gamma t}\right]^{1 / \alpha}\right.$. Similarly the problem of an $i$ th imitating firm of a product at age $s$ is given by

$$
\begin{aligned}
V_{t}^{i}(s)=\max _{p_{t, s}^{i}} \int_{0}^{\infty}\left(p_{t, s}^{i} D\left(p_{t, s}^{i} ;\left[p_{t, s}^{o}, p_{t, s}^{1}, \ldots, p_{t, s}^{m_{t, s}}\right]\right)\right. \\
\left.-w_{t}\left[\frac{D\left(p_{t, s}^{i} ;\left[p_{t, s}^{o}, p_{t, s}^{1}, \ldots, p_{t, s}^{m_{t, s}}\right]\right)}{A e^{\gamma t}}\right]^{1 / \alpha}\right) e^{-\delta t} d t
\end{aligned}
$$

\subsection{Equilibrium}

There is symmetry across producers (both the innovator and the imitators). Let $t_{i}$ denote the time difference between dates at which the innovator and the $i$ th imitator start producing. In equilibrium, due to free entry no innovator or imitator should make any profits. Consider the value of an innovating firm at the date of innovation, $V_{t}^{o}(0)$. Since the first imitator imitates $t_{1}$ units of time after innovation date, the innovator produces the product alone as a monopolist between time $t$ and $t+t_{1}$. Let $\Pi_{t+j}^{o}, 0 \leq j \leq t_{1}$ denote the profit stream of the innovator between time $t$ and $t+t_{1}$. Since there won't be any difference between the innovating firm and any imitator, the value of the imitating firm when the first imitator imitates should be equal to the value of the first imitating firm at that date. Therefore,

$$
V_{t}^{o}(0)=\int_{0}^{t_{1}} \Pi_{t}^{o} e^{-\delta t} d t+e^{-\delta t_{1}} V_{t+t_{1}}^{1}\left(t_{1}\right),
$$

Similarly, between time $t+t_{1}$ and $t+t_{2}$ the innovating firm and the first imitator produce in the market together. Let $\Pi_{t+j}^{1}, t_{1} \leq j \leq t_{2}$ denote the profit stream of these firms during that time. Hence, 


$$
V_{t+t_{1}}^{1}\left(t_{1}\right)=\int_{t_{1}}^{t_{2}} \Pi_{t+y}^{1} e^{-\delta\left(y-t_{1}\right)} d y+e^{-\delta\left(t_{2}-t_{1}\right)} V_{t+t_{2}}^{2}\left(t_{2}\right),
$$

In general, the value of the $i$ th imitator will be given by

$$
V_{t+t_{i-1}}^{i}\left(t_{i-1}\right)=\int_{t_{i-1}}^{t_{i}} \Pi_{t+y}^{i} e^{-\delta\left(t_{i}-t_{i-1}\right)} d y+e^{-\delta t_{i+1}} V_{t+t_{i+1}}^{i+1}\left(t_{i}\right) .
$$

In equilibrium if there is product innovation the cost of innovation has to be equal to the value of an innovating firm, i.e.,

$$
\kappa=V_{t}^{o}(0)
$$

if there is product innovation at time $t$. Also in equilibrium if $i$ th imitator of a product imitates at product age $s$ then the cost of imitation has to be equal to the value of imitation, i.e.,

$$
C(s)=\lambda \kappa e^{-\rho s}+(1-\lambda) \kappa=V^{i}(s),
$$

Using these equilibrium conditions, it follows that, in equilibrium,

$$
\begin{gathered}
\begin{aligned}
\int_{0}^{t_{1}} \Pi_{t}^{o} e^{-\delta t} d t & =\kappa-e^{-\delta t_{1}} C\left(t_{1}\right) \\
& =\kappa-e^{-\delta t_{1}}\left[\lambda \kappa e^{-\rho t_{1}}+(1-\lambda) \kappa\right] \\
& =\kappa\left(1-\lambda e^{-(\rho+\delta) t_{1}}-(1-\lambda) e^{-\delta t_{1}}\right)
\end{aligned} \\
\int_{t_{1} \quad \Pi_{t+y}^{t_{2}} e^{-\delta\left(y-t_{1}\right)} d y=}=C\left(t_{1}\right)-e^{-\delta\left(t_{2}-t_{1}\right)} C\left(t_{2}\right) \\
=\left[\lambda \kappa e^{-\rho t_{1}}+(1-\lambda) \kappa\right]-e^{-\delta\left(t_{2}-t_{1}\right)}\left[\lambda \kappa e^{-\rho\left(t_{2}-t_{1}\right)}+(1-\lambda) \kappa\right] \\
=\kappa\left(\lambda e^{-\rho t_{1}}+(1-\lambda)-\lambda e^{-(\rho+\delta)\left(t_{2}-t_{1}\right)}-(1-\lambda) e^{-\delta t_{1}}\right)
\end{gathered}
$$

The condition for optimal imitation date for an imitating firm will be as follows. Consider the imitation time decision of the $i$ th imitator. Assuming that the number of imitators in the lifetime of the product is more than $i$, the $i$ th imitator should be indifferent about postponing its date of imitation by a small period of time. So

$$
\frac{d\left(V^{i}(s)\right)}{d s}=\Pi^{i}-(1-\lambda) \delta e^{-\rho s} \kappa-(\rho+\delta) \lambda \kappa e^{-(\rho+\delta) s}=0 .
$$

Integrating both sides of this condition between $t_{i}$ and $t_{i+1}$ yields the no-profit condition 


$$
\begin{aligned}
\int_{t_{i}}^{t_{i}+t_{i+1}} \Pi_{t}^{i} e^{-\delta t} d t & =e^{-\delta t_{i}} C\left(t_{i}\right)-e^{-\delta t_{i+1}} C\left(t_{i+1}\right) \\
& =\kappa\left(\lambda e^{-\rho t_{i}}+(1-\lambda)-\lambda e^{-(\rho+\delta) t_{i}}-(1-\lambda) e^{-\delta t_{i}}\right)
\end{aligned}
$$

Therefore once the no-profit conditions hold, the optimality conditions for the imitation time decisions for the imitators will also hold. Using these conditions the equilibrium pattern of imitations can be computed.

Until the first imitator starts to produce the innovator enjoys pure monopoly. So he picks its price with a markup equal to $1 / \theta$ as a monopolist would do. Let's consider what would happen when the first imitator also starts to produce. Two producers the innovator and the imitator will be playing the Bertrand Game. Since the production function exhibits decreasing returns to scale one may think that the equilibrium will be one with marginal cost pricing where

$$
p^{o}=p^{1}=p^{*}=\frac{w}{f^{\prime}(n)} .
$$

However that won't be a Nash equilibrium. It is easy to show that there are prices $p>p^{*}$ that yield a higher profit for a firm given that the other firms charge $p^{*}$. This problem can be handled by assuming that firms have to satisfy all the demand at the price that they pick. In that case a firm will not gain from charging a price higher than $p^{*}$, in fact it will lose all of its potential customers like in the competitive situation. In general then with this assumption, if there are $m>1$ producers, their charging

$$
p^{o}=p^{1}=\ldots=p^{m-1}=p^{*}=\frac{w}{f^{\prime}(n)} .
$$

will be a Nash Equilibrium.

It is easy to show that the employment in this economy is constant at $n=$ $\phi$. So total output at time $t$ will be $y_{t}=\gamma^{t} A \phi^{\alpha}$. In equilibrium all products of the same age will have the same price.

Let $p_{s}, m_{s}, y_{s}$ denote the price, the number of producers and the total output of an age-s product in equilibrium. The following proposition states that for $0<$ $\lambda<1$ and $\rho>0$, the number of producers, total output will be increasing whereas the price of the product will be decreasing through time. After some time though there will not be anymore entry and the price and output from then on will be constant. If, on the other hand, $\lambda=1$, i.e., all of the entry cost is $R \& D$ cost, assuming that, $0<\alpha<1$, entry will not ever stop and price and output will always be increasing. The intuition is simple. As long as $\lambda>0$, the entry cost will converge to $(1-\lambda) \kappa>0$, as the product ages, but the benefit from entry is always strictly decreasing in the number of producers. Therefore there will always be a finite number of entrants, after which entry will bring strictly negative net profits. 
Proposition 1: Assume that $0<\lambda<1$ and $\rho>0$. In equilibrium, $p_{s} \leq p_{s-1}$, $m_{s} \geq m_{s^{-1}}$, and $y_{s} \geq y_{s^{-1}}$. There exists an age $s^{o}$ after which price, number of producers and total output of a product is constant, i.e., $p_{j}=p^{o}, m_{j}=m^{o}$, and $y_{j}=y^{o}$ for $j \geq s^{o}$.

The fraction of entry cost that actually goes to $\mathrm{R} \& \mathrm{D}, \lambda$, affects the equilibrium innovation and imitation decisions very crucially. The following proposition compares the equilibrium in two economies with different $R \& D$ shares in the entry cost. Consider these two economies at a common number of products. It can be shown that the present value of all future profits from innovating one more products is higher in the low $\lambda$ economy. Therefore, in equilibrium, number of products in the low $\lambda$ economy will be higher. In both economies entry cost will erode through time after innovation and will converge to $(1-\lambda) \kappa$. As entry cost converges down to $(1-\lambda) \kappa$ the number of imitators also converges to a fixed number, $m^{\circ}$. Since eventual cost of entry is lower in the high $\lambda$ economy, $m^{o}$ should be higher. Therefore it can be shown that the eventual number of producers, and eventual total output will be higher, whereas, the eventual price will be lower in the high $\lambda$ economy. Naturally, then, concentration given as the share of the largest some number of producers in the total industry output will be lower in the high $\lambda$ economy. Interestingly, although the final number of imitators, and output is high, and the final price is low in the high $\lambda$ economy, there is no monotonicity in this relationship. It can be shown that, up to some time after innovation, the number of imitators is actually lower in the high $\lambda$ economy. This is because higher $\lambda$ gives more incentive to postpone the imitation dates initially.

Proposition 2: Consider two economies without government protection identical except for $\lambda$. Let the fraction of innovation cost that goes to research, $\lambda$, be higher in the second economy, $\lambda_{1}<\lambda_{2}$. Then, in equilibrium; a) the number of goods will be higher in the low $\lambda$ economy, $b$ ) concentration will be lower in the high $\lambda$ economy, $c) m_{1}^{o} \leq m_{2}^{o}, p_{1}^{o} \geq p_{2}^{o}$, and $y_{1}^{o} \leq y_{2}^{o}$, d) there exists a time $x$ after innovation such that $m_{1}^{t} \geq m_{2}^{t}, y_{1}^{t} \geq y_{2}^{t}$, and $p_{1}^{t} \leq p_{2}^{t}$ for $0 \leq t<x$, whereas, $m_{1}^{t} \leq m_{2}^{t}, y_{1}^{t} \leq y_{2}^{t}$, and $p_{1}^{t} \geq p_{2}^{t}$ for $t>x$.

Another important factor that shapes the innovation and imitation decisions is the extent of decreasing returns in the production function. Without enough decreasing returns, imitation leads to a dead end for both the innovating and the imitating firms. As long as $\lambda<1$, or, $\rho$ is finite, the innovating firm has the upper hand in this setup and absence of decreasing returns deters all future imitation. Strong decreasing returns on the other hand invites imitation because there is room for enough profits even though the firms are competing perfectly. The following proposition compares two economies identical except for the extent of returns to scale. Since the lack of decreasing returns deters imitation, 
it allows the innovator to appropriate the innovation cost more easily. Therefore in an economy where the production technology exhibits less decreasing returns innovation will be more attractive. In equilibrium, there will be more innovation and products in an such an economy.

PROPOSITION 3: Consider two economies without government protection identical except for $\alpha$. Let the extent of decreasing returns be higher in the second economy, i.e., $\alpha_{1}>\alpha_{2}$. Then, in equilibrium; a) number of goods will be higher in the high $\alpha$ economy, $b) t_{i}^{2}<t_{i}^{1}$, imitation will be earlier in the low $\alpha$ economy; c) price decline will be faster in the high $\alpha$ economy; d) concentration will be lower in the high a economy.

In the following section we parameterize the model economy and solve it as a numerical example.

\subsection{A Numerical Example}

$\begin{array}{ll}\text { Technology parameters } & A=1, \gamma=.02, \alpha=0.5 \\ \text { Preference parameters } & \delta=0.04, \phi=0.3, \theta=0.2 \\ \text { Innovation and imitation } & \kappa=10, \lambda=0.5, \rho=.2\end{array}$

We use the following parameterization as the benchmark.

First we study the effects of $\lambda$ on equilibrium innovation and imitation. Let's solve the benchmark economy and a second economy which is identical to the benchmark one except a larger fraction of entry cost is R\&D cost. Let $\lambda=$ 0.75 for the second economy. Figure 1 plots the imitation profiles for these economies. It takes around 8 units of time in the low $\lambda$ economy before a new product matures (imitation stops) whereas it takes 13 units of time in the high $\lambda$ economy. The final number of imitators and producers is 20 for the economy with $\lambda=0.5$, whereas it is 55 for the economy with $\lambda=0.75$. So eventually the concentration of the market for a product is lower for the high $\lambda$ economy. But, the evolution of the industry is such that there it is a lot more concentrated early on when the number of imitators is lower, - proposition 1, part d. For high $\lambda$, there is more incentive for an imitator to wait initially because for each unit of time he waits his cost of entry goes down by $\rho \lambda \kappa e^{-\rho}$ amount which is increasing in $\lambda$. Therefore higher $\lambda$ provides more incentive for an innovator to postpone the date of imitation. But eventually number of imitators becomes higher. Figure 2 plots total amount of output of a product during its life cycle in these two economies. Again eventual output is higher in the high $\lambda$ economy but during 


\section{Number of Producers}

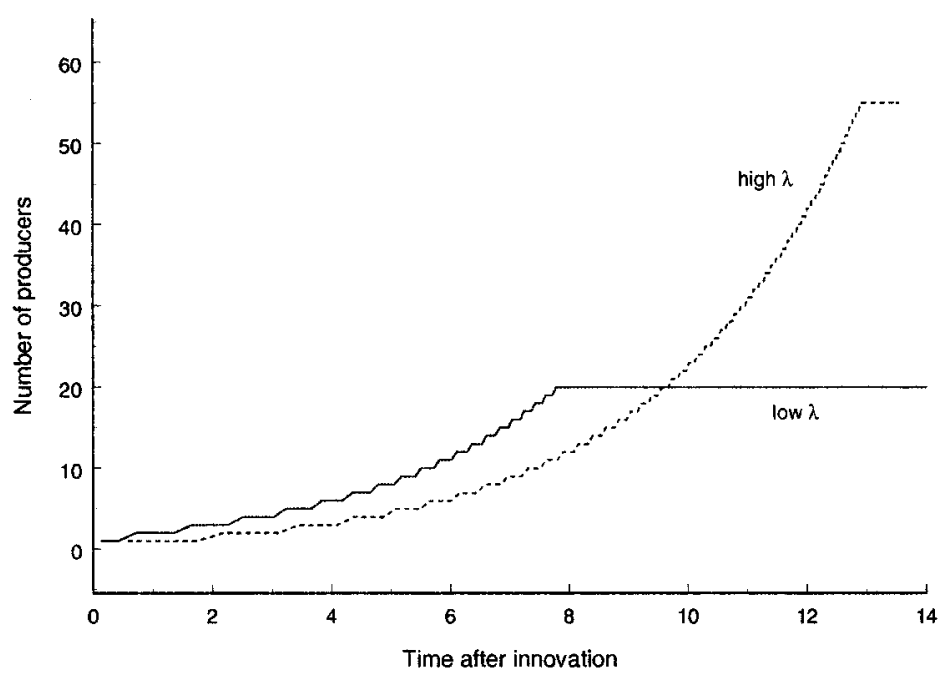

Figure 1. Number of Producers Along the Life Cycle of a New Product

transition to maturity less output is supplied to the market for a while. Figure 3 gives the price of a product during its life cycle in the high and low $\lambda$ economies. Prices in both economies when only the innovating firm is producing are the

\section{Total Quantity Produced}

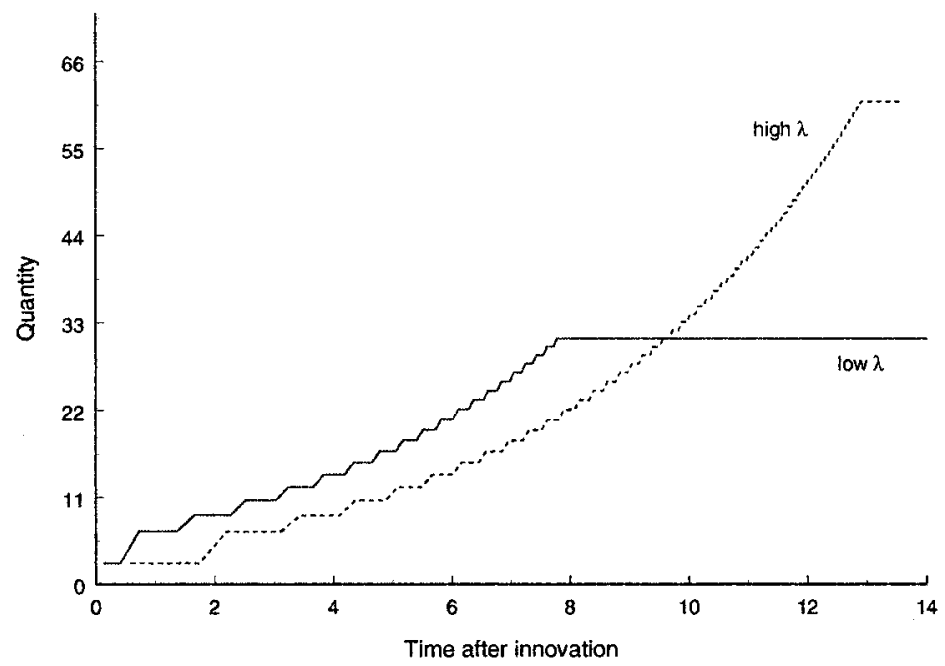

Figure 2. Total Output Supplied Along the Life Cycle of a Product 


\section{Price of a New Product through Time}

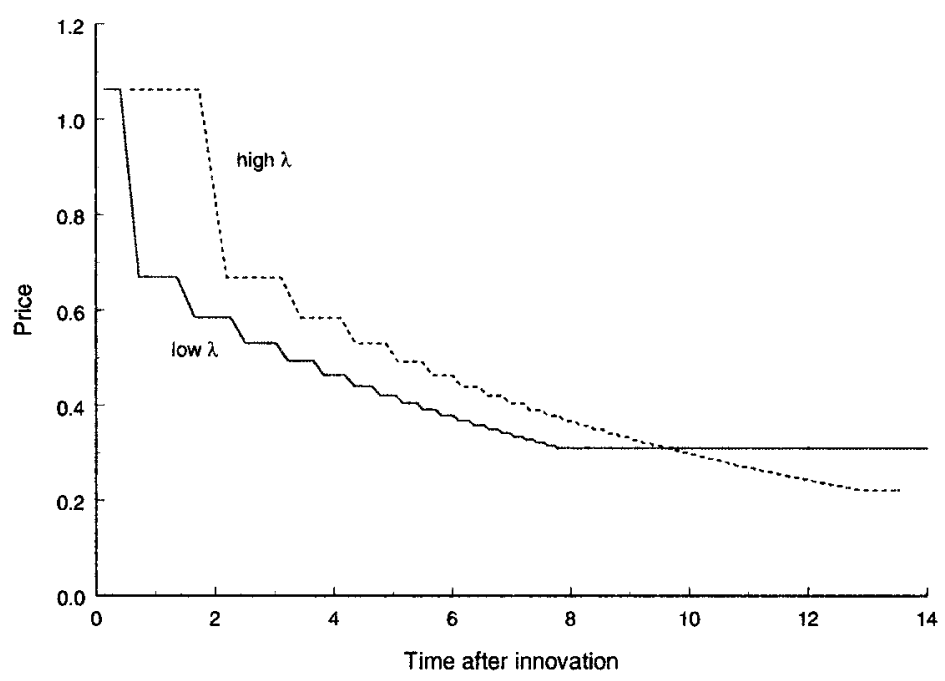

Figure 3. Price of a New Product Through Time

same, therefore initial prices are the same. The prices charged eventually after imitation stops is lower for the high $\lambda$ economy. Since total output supplied to the market is initially low in the high $\lambda$ economy, the equilibrium price is higher for a while compared to the low $\lambda$ economy. So newer goods are more expensive initially, but cheaper eventually when they are old in the high $\lambda$ economy compared to the low $\lambda$ one. Figure 4 shows the profits per producer during the life cycle in the high and low $\lambda$ economies. Final profits after the product matures are lower in the high $\lambda$ economy because of the larger number of competitors. However initially when the product is new it brings more profits to the producers in the high $\lambda$ economy. The second important factor that shapes the equilibrium innovation and imitation is the extent of decreasing returns. We solve the model economy for $\alpha=0.5$ (the benchmark case) and $\alpha=0.3$. Figure 5 plots the evolution of the number of imitators for a new product. The total number of producers is monotonically higher-therefore concentration is lower-in the low $\alpha$ (stronger decreasing returns) economy. Figure 6 shows total output produced during the life cycle of a new good. Although number of producers is higher in the low $\alpha$ economy total output supplied is monotonically higher in the high $\alpha$ economy. Although these two margins of production (number of firms vs. amount each firm produces) work in opposite directions, since entry is costly total output supplied in the high $\alpha$ economy is always higher. Figures $7-8$ give the price of a new product and profits per firm during the life cycle of a new good. Prices are lower in the economy with weaker decreasing returns whereas profits are higher. 


\section{Profits}

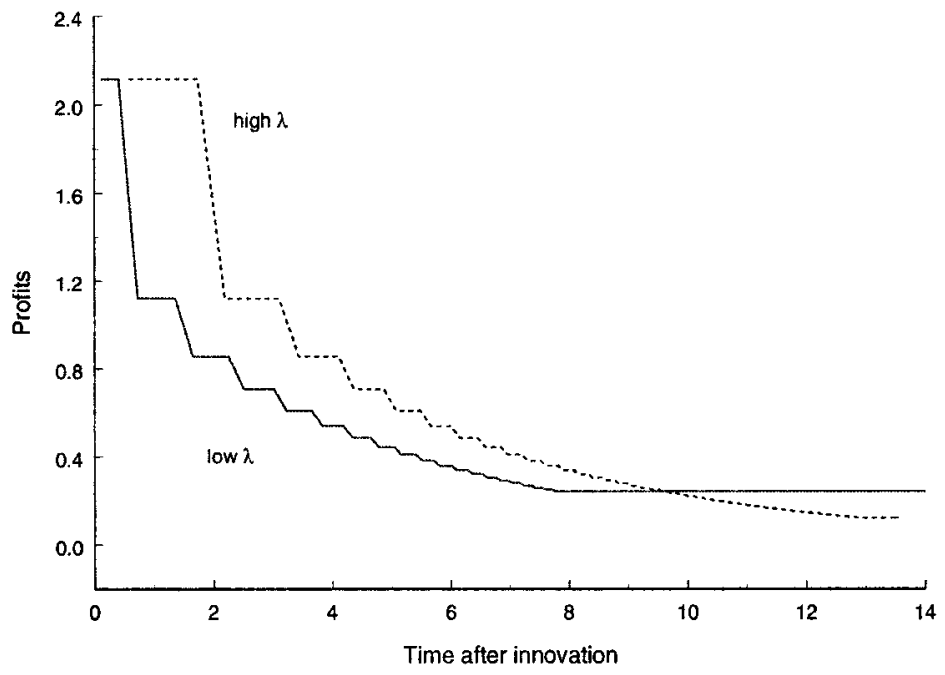

Figure 4. Profits per Firm Along the Life Cycle of a Product

\section{Number of Producers}

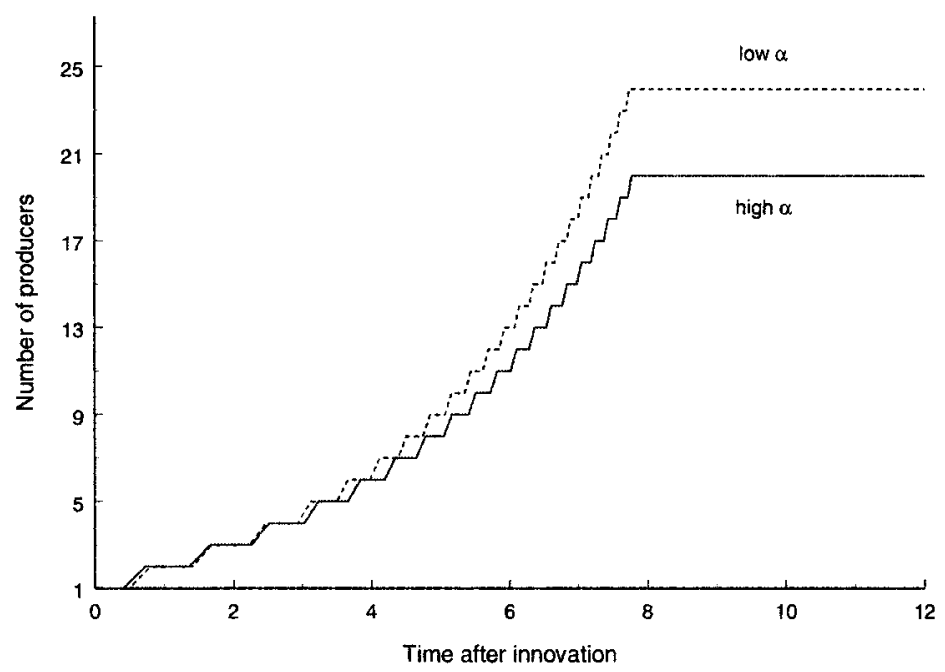

FiguRE 5. Number of Producers Along the Life Cycle of a New Good 


\section{Total Quantity Produced}

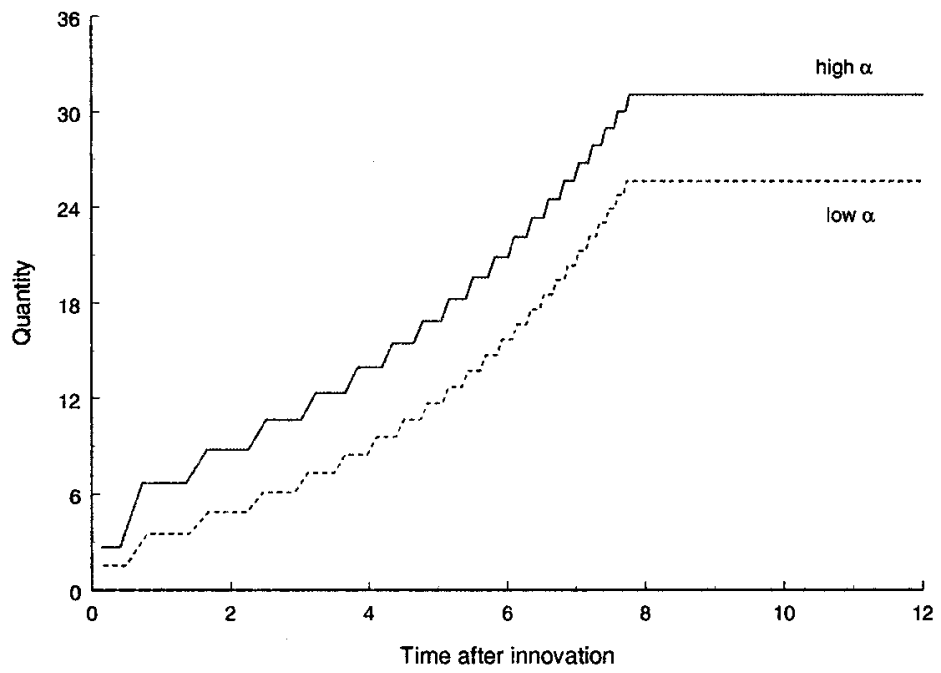

Figure 6. Total Quantity of Output Supplied to the Market

\section{Price of a New Product through Time}

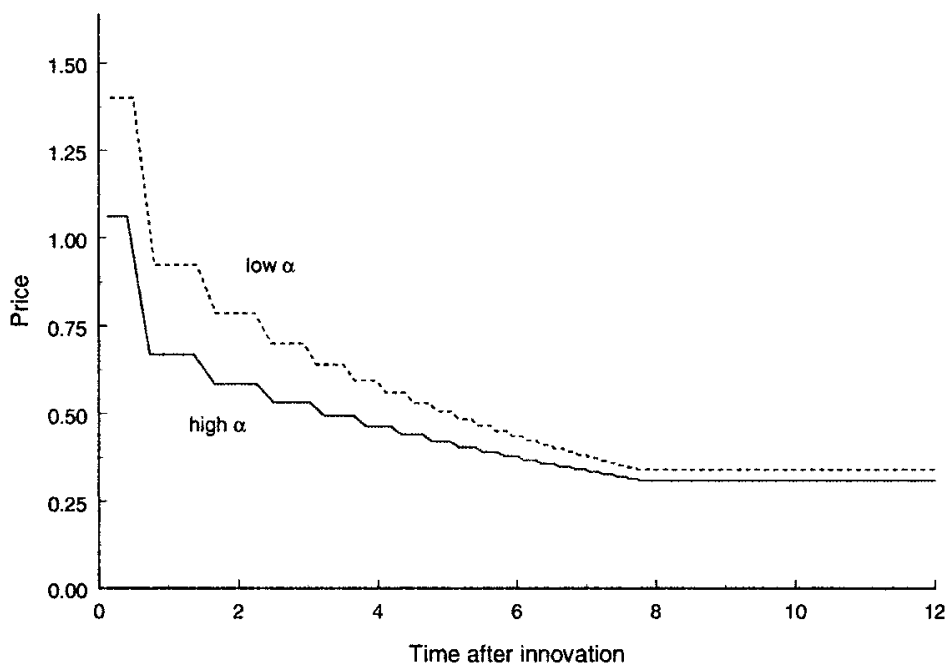

FIgURE 7. Price of a New Good Along Its Life Cycle 


\section{Profits}

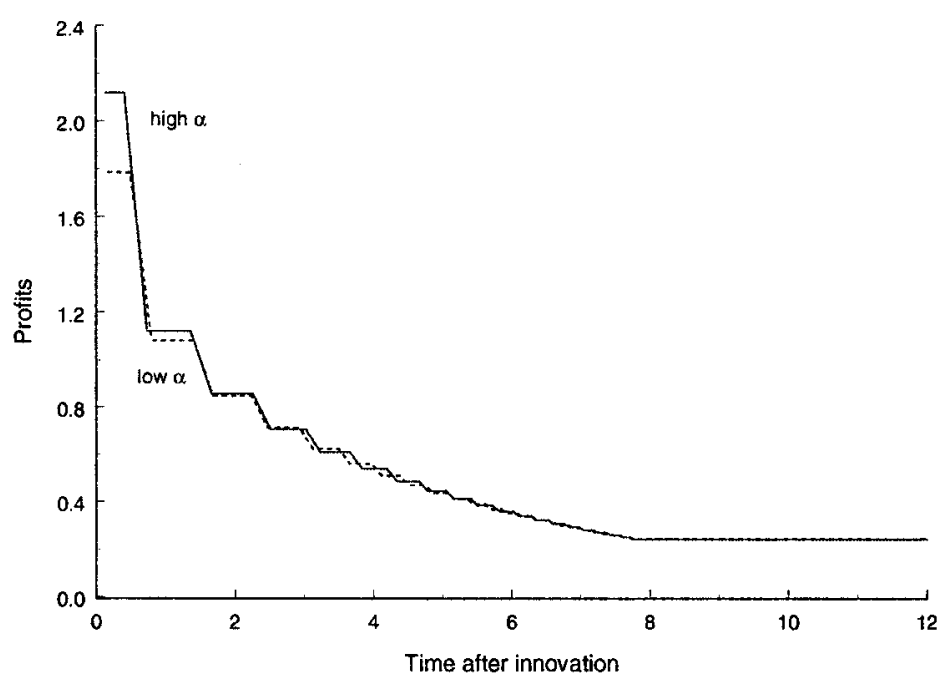

FIgure 8. Profits per Firm Along the Life Cycle of a New Good

\section{Conclusion}

The numerical example shown here illustrates that the process of innovation, imitation and industry evolution are very different for different types of goods. High information content goods, i.e., those that require proportionately more R\&D to create lead to a very different structure of industry and industry evolution. These findings are all in the context of a world where there are no regulations or legal restrictions that inhibit imitation other than the cost of doing so. The fact that the behavior of industry is so different for high information content goods suggest that optimal policies for protecting ideas should be very different for high information content goods. We address these ideas in another paper.

\section{References}

Cooley, Thomas F. and Mehmet Yorukoglu (2002). "The New Economy: Some Macroeconomic Implications of an Information Age." Working paper, University of Chicago.

Mansfield, Edwin, Mark Schwartz, and Samuel Wagner (1981). "Imitation Costs and Patents: An Empirical Study.” The Economic Journal, 91, pp. 364, 907-918. 
Copyright of Journal of the European Economic Association is the property of MIT Press and its content may not be copied or emailed to multiple sites or posted to a listserv without the copyright holder's express written permission. However, users may print, download, or email articles for individual use. 